\title{
Neutron tomography of ancient lead artefacts $\uparrow$
}

Cite this: Anal. Methods, 2014, 6, 2390

Received 6th November 2013 Accepted 23rd December 2013

DOI: $10.1039 / c 3 a y 41967 c$

www.rsc.org/methods

\author{
R. Triolo, ${ }^{a}$ F. Lo Celso, ${ }^{\star b}$ P. Tisseyre, ${ }^{c}$ N. Kardjilov, ${ }^{d}$ F. Wieder, ${ }^{e}$ A. Hilger ${ }^{d}$ and I. Manke ${ }^{d}$
}

The investigations presented here show the results of an epigraphic analysis on ancient Roman lead ingots rescued from shipwrecks along the coast of Sicily (Italy) by means of Neutron Tomography (NT). The artefacts, including a lead horn, can be dated back to a period between the $3^{\text {rd }}$ and $1^{\text {st }}$ century BC. The three dimensional NT reconstructions helped the decipherment of hidden signs and partially visible details on the severely damaged objects. The findings obtained using the non-destructive procedure allowed us also to reach plausible conclusions in the context of the known commercial routes.

\section{Introduction}

Neutron tomography is a universal non-destructive method for investigation of the inner structure of bulky samples. ${ }^{1-8}$ The reconstruction of the volume is based on the collection of $2 \mathrm{D}$ transmission projections of the sample over an angular interval of $180^{\circ}$ or $360^{\circ} .{ }^{9}$ The transmission through the sample depends on its thickness $(d)$ and local attenuation coefficient $(\mu)$ as shown in eqn (1), the Lambert-Beer law:

$$
T=I / I_{0}=\mathrm{e}^{-\mu d}
$$

where $T$ is the transmission, i.e. the ratio between $I_{0}$ and $I$, the intensities of the incident and of the transmitted neutrons, respectively. The attenuation coefficient depends on the interaction process between the radiation and the matter. For low energetic neutrons (thermal or cold) the attenuation coefficients of the elements do not depend on their atomic number as in the case of $\mathrm{X}$-rays due to the fact that the neutrons interact with the nuclei and the X-rays with the electrons of the atom. In contrast to the X-rays the neutron beam is attenuated strongly by light elements like hydrogen, lithium and boron and transmitted easily for metals like iron and nickel. ${ }^{10}$ Even for heavy elements like lead $(\mathrm{Pb})$ very high transmission is observed. These unique properties of neutron radiation are used in many experiments for determination of water (hydrogenous substances) in different devices like fuel cells $s^{11,12}$ and visualization of mass transport in lithium batteries. ${ }^{13,14}$ Many other applications related to the unique properties of the neutron were reported recently on different fields. ${ }^{15-17}$

\footnotetext{
aDipartimento di Chimica Fisica "S. Cannizzaro", Università degli Studi di Palermo, Italy

${ }^{b}$ Dipartimento di Fisica e Chimica, Università degli Studi di Palermo, Italy. E-mail: fabrizio.locelso@unipa.it

'Servizio Soprintendenza per i Beni Culturali e Ambientali del Mare, Regione Siciliana, Palermo, Italy

${ }^{d}$ Helmholtz-Zentrum Berlin, Germany

${ }^{e}$ Technische Universität Berlin, Germany

$\dagger$ This article is dedicated to the memory of Roberto Triolo.
}

Neutron imaging is very well suited for investigation of samples of cultural heritage due to the high penetration depth of neutron radiation in comparison to X-rays..$^{3-5}$ This property of a neutron beam allows for investigation of real samples with dimensions of $100 \mathrm{~cm}^{3}$ and even more. The sensitivity to hydrogenous substances helps to visualize organic materials like leather, wood and textile within a metal environment. ${ }^{18,19}$ Lead is almost transparent to neutrons. Therefore neutron imaging is indispensable for the investigation of bulky lead samples. The attenuation coefficient for lead is $0.37 \mathrm{~cm}^{-1}$ which means that a thickness of $c a .2 \mathrm{~cm}$ reduces the beam intensity by about a half. If we assume that the largest thickness of a lead sample investigated by neutrons should transmit at least $10 \%$ of the initial beam, in order to have an acceptable signal to noise ratio in the image (see eqn (1)) one can get a maximal acceptable sample thickness of $T_{10 \%}=(\ln 0.1) / \mu=6.2 \mathrm{~cm}$. A comparison of attenuation coefficients and $T_{10 \%}$ values for different materials as typically found in samples of cultural heritage is shown in Table 1. As a conclusion it could be stated that lead is the metal with one of the highest neutron transmissions among the cultural heritage relevant metals. This allows for investigation of large samples by neutron tomography which seems to be the most successful method for non-destructive study of the inner structure of bulky archeological lead samples. In this paper we report a NT investigation on two different kinds of lead ingots belonging to Roman shipwrecks discovered in the Mediterranean sea around Sicily (Italy). Although heavily damaged the NT experiment has shown, after a digital 3D reconstruction, the original mold marks. This allowed us to establish the producer and the mine site. Another sample, a lead horn, coming also

Table 1 Linear attenuation coefficients of some metals for thermal neutrons

\begin{tabular}{lllllllll}
\hline Material & $\mathrm{Au}$ & $\mathrm{Ag}$ & $\mathrm{Cu}$ & $\mathrm{Sn}$ & Bronze & $\mathrm{Pb}$ & $\mathrm{Zn}$ & $\mathrm{Fe}$ \\
\hline$\mu\left[\mathrm{cm}^{-1}\right]$ & 6.28 & 3.99 & 0.99 & 0.20 & 0.87 & 0.37 & 0.34 & 1.20 \\
$T_{10 \%}, \mathrm{~cm}$ & 0.4 & 0.6 & 2.3 & 11.5 & 2.6 & 6.2 & 6.8 & 1.9
\end{tabular}


from a location near the Sicilian shoreline has also been investigated. The NT reconstructed data allowed valuable information about its manufacture to be uncovered. All the samples can be dated back to a period between the $3^{\text {rd }}$ and $1^{\text {st }}$ century BC.

\section{Experimental parameters}

The experiments presented in this work were performed at the neutron tomography facility CONRAD (cold neutron radiography) at the Helmholtz Zentrum Berlin (HZB). ${ }^{20}$ It is situated at the end of a curved neutron guide facing the cold source of the BER-II research reactor. The neutron guide provides a cold neutron flux in the order of app. $2 \times 10^{8} \mathrm{n} \mathrm{cm}^{-2} \mathrm{~s}^{-1}$ directly at the end of the guide with a negligible background of $\gamma$-radiation and fast neutrons. A pinhole geometry with $L / D$ of $170(L=$ $500 \mathrm{~cm}, D=3 \mathrm{~cm}$ ) was used for achieving better spatial resolution within a beam field of $10 \mathrm{~cm} \times 10 \mathrm{~cm}$ with a neutron flux of $\sim 10^{7} \mathrm{n} \mathrm{cm}^{-2} \mathrm{~s}^{-1}$. The used detector system was based on a 16-bit CCD camera (Andor) with $2048 \times 2048$ pixels. The images obtained from the LiZnS scintillator are projected via a mirror and a lens system onto the CCD chip. ${ }^{21}$

One of the lead ingots had dimensions of approximately $10 \mathrm{~cm} \times 10 \mathrm{~cm} \times 40 \mathrm{~cm}$ and a weight of $\sim 33 \mathrm{~kg}$. The surface of the samples was covered by thick corrosion layers, which were very crispy. Therefore a special sample holder was used where the contact with the sample surface was as less as possible (Fig. 1). For the tomographic measurements 300 radiographic projections at continuing rotation angles were taken over $360^{\circ}$. The exposure time per projection image was $10 \mathrm{~s}$ and the overall time for the tomographic measurement was about 1.5 hours. Due to the limited field of view of $10 \mathrm{~cm} \times 10 \mathrm{~cm}$ the sample was measured only at 3 heights where the stamps were located. For samples without visible signs on the surface the whole sample length was scanned with vertical steps of $10 \mathrm{~cm}$ (4 tomographies in total). The data were reconstructed with a back projection

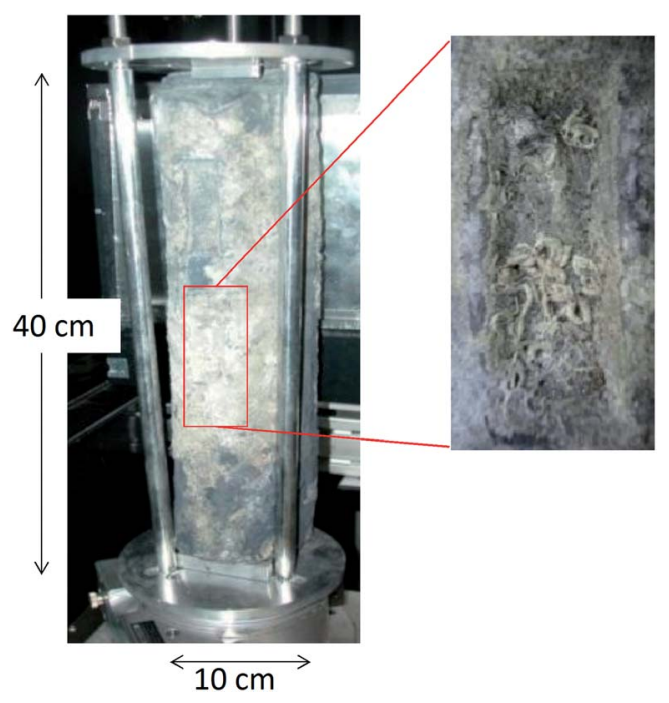

Fig. 1 Lead ingot from Siracusa in the experimental sample holder. The zoomed region refers to the middle cartouche. algorithm implemented in the software Octopus. For visualization and 3D rendering the software VGStudioMax was used. After the illumination of the samples by the neutron beam the irradiated parts become radioactive. However after some decay time the samples were approved to be non-radioactive again. In our case the necessary decay time was about 3 weeks.

\section{Results}

Here we present the epigraphic analysis, in a totally non-invasive way, of two kinds of lead ingots coming from loads belonging to sunken Roman ships near Sicily's coast (Siracusa and Messina). Tomographic reconstructions of a small ornamental horn made of lead that was rescued in shallow waters along the western Sicily shoreline (Trapani) will be shown too.

It is well established that the mining and use of lead grew very fast in the period between the $2^{\text {nd }}$ century $\mathrm{BC}$ and the $1^{\text {st }}$ century AC, due to the high demand for ship construction, both military and commercial, as well as in pipe systems for water and wastewater management. Therefore there was a heavy traffic of commercial ships that were involved in the lead trading (the ingots were used also as ballast), along the Mediterranean sea. A first group of 4 similar lead ingots, which were found under water at the same location (Siracusa, Italy ca. I BC), was characterized to have the same shape, size and weight as well as a rectangular mold mark on the top side. In Fig. 1 one of these ingots is shown which is about $40 \mathrm{~cm}$ long and has a troncopyramidal shape. It is about $10 \mathrm{~cm}$ high and about $10 \mathrm{~cm}$ wide, with a rectangular base and weight of ca. $33 \mathrm{~kg}$ (the maximum weight a slave could carry by law). It clearly shows signs of heavy damage due to deposits of salts, algae and probably carbonaceous material very likely coming from a fire that occurred on the ship. It is characterized by the presence of three regular indented rectangular areas (cartouches), on the same side, in which mold marks can be found; both characters and images are usually found in these cartouches. In this sample these areas of interest are covered by deposit and in the middle section, one could see a hint of an image (zoomed region in Fig. 1). The neutron tomography investigation provides a 3D matrix of the attenuation coefficients in the sample, which can be considered as a digitalized volume. This volume can be processed by $3 \mathrm{D}$ volume rendering software. In the case of the lead ingots the corrosion layer can be removed digitally and the original surface of the sample can be visualized non-destructively. The NT reconstruction shows that the latter represents a dolphin as shown in Fig. 2 (middle). This fact is indeed consistent with the finding, in the cartouches adjacent to the dolphin figure, of two different inscriptions in relief as shown in Fig. 2 (top and bottom parts). They read as MPLANILF, i.e. $\mathrm{M}$ (arcii) PLANI(i) L(ucii) F(ilii), and RVSSINI (Russini) ${ }^{22}$ respectively according to the tria nomina standard used mainly by Roman citizen. Indeed they were identified by a personal name, i.e. the praenomen (Marcius in its genitive form), followed by the family name, i.e. nomen (Planius in its genitive form) and then a third name, i.e. cognomen (Russini), which basically indicates a specific branch of the family. This epigraphic analysis refers therefore to the producer of the lead ingots and 
Photo
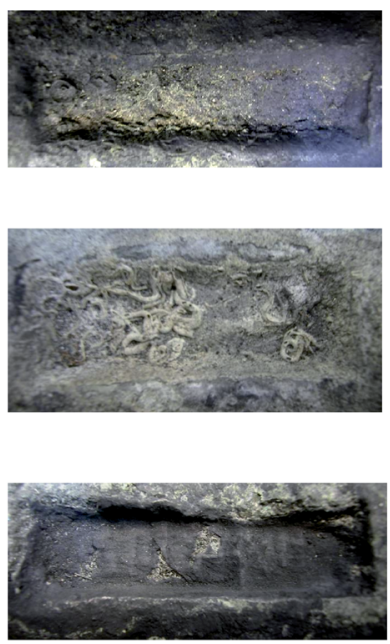

Fig. 2 Comparison between the three cartouches of lead ingot in Fig. 1; on the left the naked eye view and on the right the corresponding digitally reconstructed images.

possibly also the mine owner in Carthago Nova in Spain ${ }^{23,24}$ which dates back to the $1^{\text {st }}$ century BC, when in fact the Planius family (either Marcius or Lucius, probably brothers and sons of Lucius, as the L(ucii) F(ilii) inscription suggests) was active in lead ingot trading. In fact the latter were found in shipwrecks in many locations along the coasts of Italy and France.

Similar characteristics were found in the other three ingots, which by the naked eye also appear to have partially erased mold marks. The second lead ingot, as shown in Fig. 3a, has a
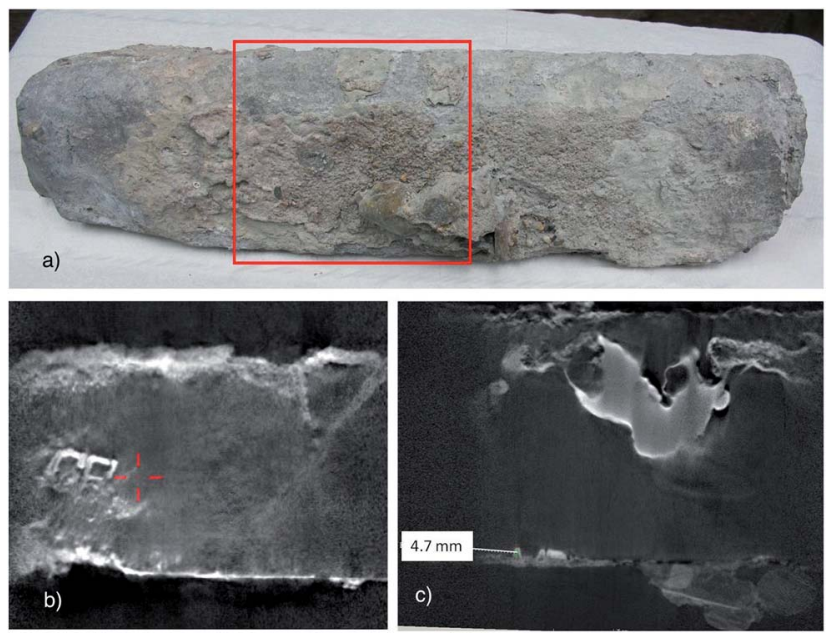

Fig. 3 (a) Picture of the whole lead ingot depicting its highly damaged state, concretions are clearly observable. (Red square) The area in one of the slanted sides where signs were found after the digital reconstruction is also marked; (b) from the digital reconstruction a group of two letters as well as a big cross-sign (not visible by the naked eye) were found. The red mark on the image shows the position of the cutting plane for the cross-section shown in subsection (c); (c) top view of the slanted side where the letters were found showing the shape and the depth of stamping marks. different shape in the cross-section compared to the one described in Fig. 1, different length and weight (length of $35 \mathrm{~cm}$ and weight of $\sim 30 \mathrm{~kg}$ ); the sample was a part of a load rescued in Capo Rasocolmo Messina (Italy) that could probably date back to the $3^{\text {rd }}$ century BC. It is possible to see that it has slanted sides and a rounded top while the base is still rectangular. The sample is heavily covered by calcareous concretions which in some parts include small spherical shaped stones (see the protrusion in the lower right part of Fig. 3c). There are two regions of interest beneath the calcareous concretion in one of the slanted sides. It is possible to see, in Fig. 3b, a big X shaped sign running across the whole width of the ingot, while about $10 \mathrm{~cm}$ away there is a group of characters which could lead to a possible identification of the maker. The group of characters can be read as CP which can be probably traced back to one of the Cartagena's producers C(aius) $\mathrm{P}$ (ontileieni) which is contemporary to the Planius family. Indeed it has been found around the $3^{\text {rd }}$ century $\mathrm{BC}^{25}$ that some of the ingots produced by the Planius family have been stamped as well with the Marcus Caius Pontilieni inscription. The big X shaped sign is probably a mark for the production or trade control. In Fig. 3c it is also shown in the vertical projection that the letters have been stamped, the depth of the stamp is $4.7 \mathrm{~mm}$ and it is triangularly shaped.

Furthermore here we report the NT reconstruction of a small lead ornament horn, which was found along the seashore in western Sicily (Petrosino, Trapani). Fig. 4a shows a picture of the lead horn. It is approximately $25 \mathrm{~cm}$ long and its section is elliptical (at its base it is $5.7 \mathrm{~cm} \times 7.6 \mathrm{~cm}$, minor and major axes respectively). It is characterized along its length by 4 rows of nearly regularly spaced holes (18 in total) with a nearly $8 \mathrm{~mm}$ square section. This horn was probably placed on the ship for

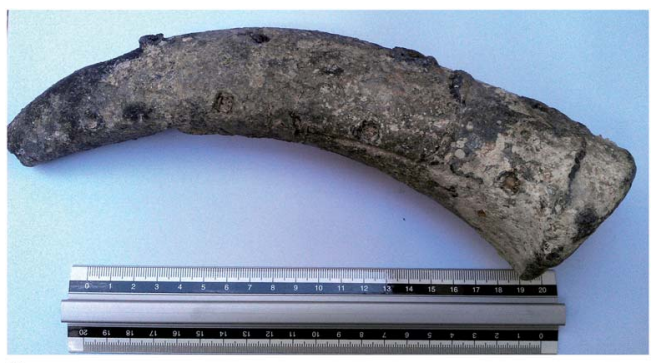

a

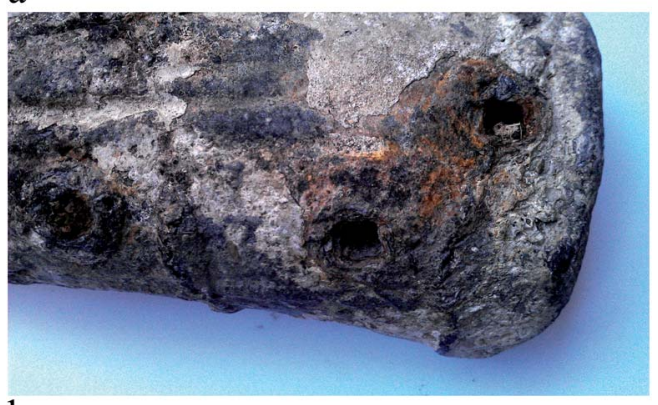

b

Fig. 4 (a) Lead horn rescued near the western Sicily shoreline (Petrosino, Trapani). (b) A zoomed region (bottom part) of the lead horn of the previous figure. 
holding decorations or was decorated itself or was part of a more elaborate decoration. It is also possible that this lead object was a filling part of a real bovine horn. Indeed not only sizes are comparable but also in some cases remaining materials of the real horn were found. ${ }^{26,27}$ The choice of lead was probably due to the fact that it has a lower melting point with respect to copper or bronze and furthermore scientific evidence shows that pouring molten lead into a horn cavity does not produce damage to the horn itself. ${ }^{27}$ The holes are due to the presence of the nails that were put in place immediately after the pouring of molten lead, while it was still malleable. Indeed driving a nail through solid lead is not only very difficult but it would have caused heavy deformation in the lead body. Furthermore the nails have left imprints of their head on the exterior curved part of the horn meaning that they were applied from the convex part. It is also possible to see two parallel protruding lines in the bottom part of the horn that were caused by the fact that it needed to be mounted to another structure of the ship. In Fig. 4b it is possible to see the detail of some holes and some stripes in the lead body that are due to the production process. Fig. 5 shows the NT digital reconstruction from different angles and at different zooming levels. It is interesting to see the oblique orientation of the holes (i.e. the space occupied by the dissolved nails) with respect to the main axis of the horn mostly pointing towards its base, as well as their length (approx. $3.5 \mathrm{~cm}$ ) and density along the horn. A detail from the bottom part section of the horn is shown in Fig. $5 \mathrm{~b}$ and c, where it is possible to clearly see the shape of the nails (quadratic

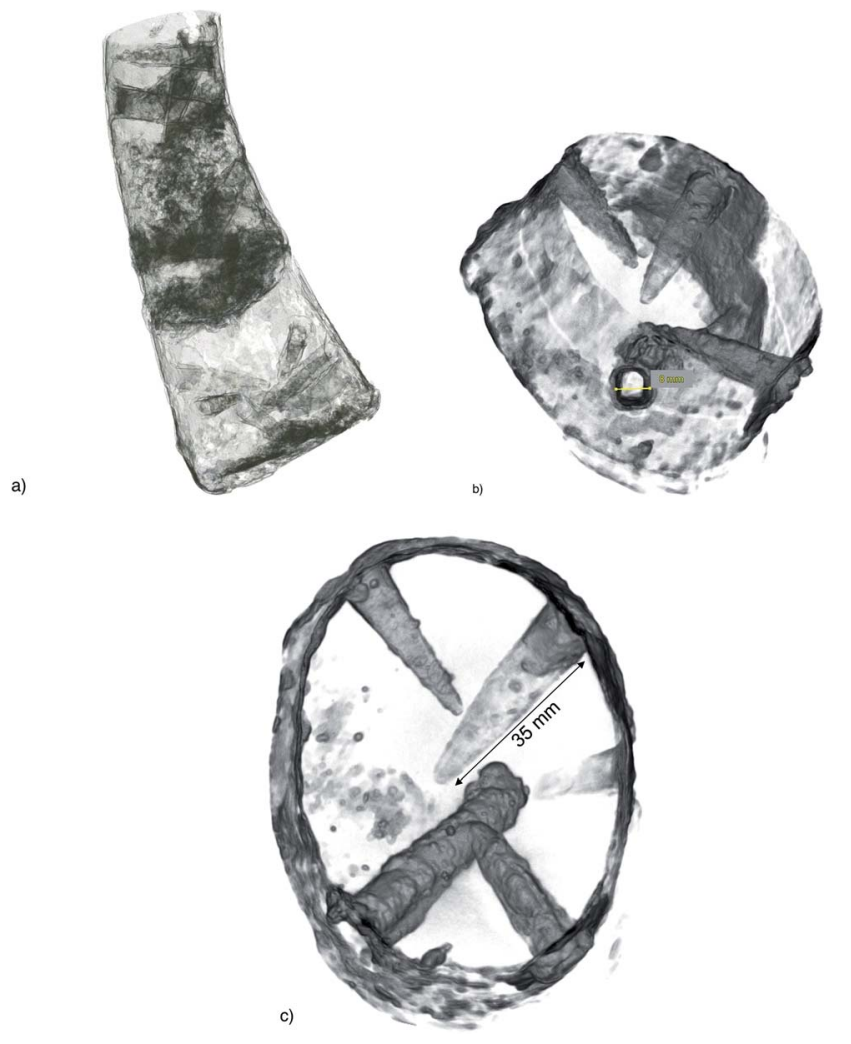

Fig. $5(a-c)$ NT reconstruction of the lead horn in Fig. 4a. cross-section) as well as the size of their heads (approx. $8 \mathrm{~mm}$ ). The manufacture of this lead horn is analogous to other similar finds in the Mediterranean area, and it also may suggest that it could belong to Roman or Greek ships. Only two of them can be certainly dated. They belong to the Albenga and Punta Scaletta shipwrecks, between 140 and $130 \mathrm{BC}$ and 100 and $80 \mathrm{BC}$ respectively. ${ }^{26,28}$

\section{Conclusions}

The work presented here gives a full perspective on the possibilities offered by neutron tomography in the field of archeological investigation. The technique has been applied to severely damaged lead ingots rescued from underwater shipwrecks, and it has given final answers both on the provenance and the historical timeframe in which the ingots were traded. A lead horn which also came from a shipwreck was also investigated thus giving evidence of its manufacture and therefore of its time window of production. It is very important to underline that the NT technique allowed us not only to examine rather bulky samples, but thanks to its selectivity towards different elements, it also made it possible to digitally retrieve precious information in a non-destructive way.

\section{References}

1 N. Kardjilov, I. Manke, A. Hilger, M. Strobl and J. Banhart, Mater. Today, 2011, 14, 248-256.

2 N. Kardjilov, A. Hilger, I. Manke, M. Strobl, M. Dawson and J. Banhart, Nucl. Instrum. Methods Phys. Res., Sect. A, 2009, 605, 13-15.

3 N. Kardjilov, A. Hilger, I. Manke, V. Benfante, F. Lo Celso, R. Triolo, I. Ruffo and S. Tusa, Notiziario Neutroni e Luce di Sincrotrone, 2008, 13, 6-9.

4 N. Kardjilov, F. Fiori, G. Giunta, A. Hilger, F. Rusticheli, M. Strobl, J. Banhart and R. Triolo, J. Neutron Res., 2006, 14, 29-36.

5 E. H. Lehmann, P. Vontobel and G. Frei, Nuovo Cimento Soc. Ital. Fis., C, 2007, 30, 93-104.

6 E. H. Lehmann, S. Hartmann and M. O. Speidel, Archaeometry, 2010, 52, 416-428.

7 B. Schillinger, E. H. Lehmann and P. Vontobel, Phys. B, 2000, 276-278, 59-62.

8 M. Strobl, I. Manke, N. Kardjilov, A. Hilger, M. Dawson and J. Banhart, J. Phys. D: Appl. Phys., 2009, 42, 243001.

$9 \mathrm{~J}$. Banhart, Advanced Tomographic Methods in Materials Research and Engineering, Oxford University Press, Oxford, UK, 2008.

10 J. Banhart, A. Borbely, K. Dzieciol, F. Garcia-Moreno, I. Manke, N. Kardjilov, A. R. Kaysser-Pyzalla, M. Strobl and W. Treimer, Int. J. Mater. Res., 2010, 101, 1069-1079.

11 I. Manke, C. Hartnig, M. Grunerbel, J. Kaczerowski, W. Lehnert, N. Kardjilov, A. Hilger, J. Banhart, W. Treimer and M. Strobl, Appl. Phys. Lett., 2007, 90, 184101.

12 C. Hartnig, I. Manke, N. Kardjilov, A. Hilger, M. Gruenerbel, J. Kaczerowski, J. Banhart and W. Lehnert, J. Power Sources, 2008, 176, 452-459. 
13 J. B. Siegel, X. F. Lin, A. G. Stefanopoulou, D. S. Hussey, D. L. Jacobson and D. Gorsich, J. Electrochem. Soc., 2011, 158, A523-A529.

14 M. Lanz, E. Lehmann, R. Imhof, I. Exnar and P. Novak, J. Power Sources, 2001, 101, 177-181.

15 N. Kardjilov, I. Manke, M. Strobl, A. Hilger, W. Treimer, M. Meissner, T. Krist and J. Banhart, Nat. Phys., 2008, 4, 399-403.

16 I. Manke, N. Kardjilov, R. Schäfer, A. Hilger, M. Strobl, M. Dawson, C. Grünzweig, G. Behr, M. Hentschel, C. David, A. Kupsch, A. Lange and J. Banhart, Nat. Commun., 2010, 1, 125.

17 M. Strobl, C. Grünzweig, A. Hilger, I. Manke, N. Kardjilov, C. David and F. Pfeiffer, Phys. Rev. Lett., 2008, 101, 123902.

18 E. Lehmann, S. Hartmann and P. Wyer, Nucl. Instrum. Methods Phys. Res., Sect. A, 2005, 542, 87-94.

19 L. Jacobson, F. C. de Beer and R. Nshimirimana, Nucl. Instrum. Methods Phys. Res., Sect. A, 2011, 651, 240243.
20 N. Kardjilov, A. Hilger, I. Manke, M. Strobl, M. Dawson, S. Williams and J. Banhart, Nucl. Instrum. Methods Phys. Res., Sect. A, 2011, 651, 47-52.

21 N. Kardjilov, M. Dawson, A. Hilger, I. Manke, M. Strobl, D. Penumadu, F. Kim, F. Garcia-Moreno and J. Banhart, Nucl. Instrum. Methods Phys. Res., Sect. A, 2011, 651, 95-99.

22 C. Domergue, Epigraphica, 1987, 49, 109-175.

23 P. R. Trincherini, C. Domergue, I. Manteca, A. Nesta and P. Quarati, 2010, arXiv:1002.3557.

24 P. Tisseyre, S. Tusa, W. R. L. Cairns, F. Selvaggio Bottacin, C. Barbante, R. Ciriminna and M. Pagliaro, Oxf. J. Archaeol., 2008, 27, 315-323.

25 F. Laubenheimer-Leenhardt, in Recherches sur les lingots de cuivre et de plomb d'époque romaine dans les régions de Languedoc-Roussillon et de Provence-Corse, de Boccard, Paris, 1973.

26 N. Lamboglia, Rivista di Studi Liguri, 1964, 30, 229-257. 27 D. Mouchot, Rivista di Studi Liguri, 1970, 36, 307-318. 28 N. Lamboglia, Rivista di Studi Liguri, 1952, 18, 131-236. 